NBER WORKING PAPER SERIES

\title{
CAN THE EUROPEAN COMMUNITY AFFORD TO NEGLECT THE NEED FOR MORE ACCOUNTABLE SAFETY-NET MANAGEMENT?
}

\author{
Edward J. Kane \\ Working Paper 11860 \\ http://www.nber.org/papers/w11860
NATIONAL BUREAU OF ECONOMIC RESEARCH
1050 Massachusetts Avenue
Cambridge, MA 02138
December 2005

\begin{abstract}
Earlier versions of this paper were presented at the following conferences: XXXV Meeting of the European Working Group on Financial Modeling, University of Brescia, Italy, Johns Hopkins University School of Advanced International Studies, Bologna Center, Bologna, Italy, and Presidential Address, International Atlantic Economic Society, New York, NY. The views expressed herein are those of the author(s) and do not necessarily reflect the views of the National Bureau of Economic Research.
\end{abstract}

(C2005 by Edward J. Kane. All rights reserved. Short sections of text, not to exceed two paragraphs, may be quoted without explicit permission provided that full credit, including @ notice, is given to the source. 
Can the European Community Afford to Neglect the Need for More Accountable Safety-Net Management?

Edward J. Kane

NBER Working Paper No. 11860

December 2005

JEL No. G21, G28, P51

\begin{abstract}
$\underline{\text { ABSTRACT }}$
As financial institutions and markets transact more and more cross-border business, gaps and flaws in national safety nets become more consequential. Because citizens of host (home) countries may be made to pay for mistakes made in the home (host) country, Basel's lead-regulator paradigm violates the principle of democratic accountability. Because important differences exist in policymaking authority, instruments, and goals, banking supervisors need to improve their ability to monitor and mitigate the consequences of defects in one another's performance. A straightforward way to enhance both capacities would be to establish opportunities for public trading in debt obligations and reinsurance derivatives issued by country-level deposit-insurance entities.

Edward J. Kane

Department of Finance

Boston College

Chestnut Hill, MA 02458

and NBER

edward.kane@bc.edu
\end{abstract}




\section{CAN THE EUROPEAN COMMUNITY AFFORD TO RESIST THE NEED FOR MORE ACCOUNTABLE SAFETY- \\ NET MANAGEMENT?* \\ Edward J. Kane \\ Boston College}

Financial-institution supervision combines a capacity to observe fluctuations in balancesheet values ("vision") with a capacity to influence managerial actions ("control") and an incentive system that governs the pursuit and exercise of these capacities. Even when portfolios and attendant risks are concentrated within a single country, it is difficult to establish a combination of adequate oversight of institutional balance sheets, adequate authority to intervene in timely fashion, and bureaucratic incentives to detect and resolve insolvent institutions in ways that adequately protect taxpayer interests. As a result, individual countries solve this contracting problem in different ways.

Sincere efforts to integrate the financial markets of individual countries must also integrate national safety nets. Safety nets are instruments for preventing and resolving financial crises. Crisis prevention and crisis management entail a right to take over insolvent financial institutions. Efforts to assess the viability of troubled institutions and to assign fair values to stakeholder claims against failing firms are rife with incentive conflict.

As European institutions and markets book more and more cross-border business, the potential for conflict grows. This is because some or all of the bill for one country's regulatory mistakes or gambles can be presented to citizens of other countries. Gaps in the jurisdiction of national regulators and supervisors can break the link between efforts to control bank and nonbank risk-taking and the allocation of losses that taxpayers might accrue in financial institution failures.

\footnotetext{
* This paper extends and refocuses analysis first presented in Kane (2003) and (2005). The author wishes to thank Richard C. Aspinwall, Bill Bergman, and Mark Flannery for helpful criticisms of an earlier draft.
} 
To keep the discussion concrete, this paper focuses on potential cross-country abuse of nation-based systems of explicit deposit insurance. However, it should be understood that this is merely the tip of a global safety-net iceberg and that past abuses of the U.S. safety net have exploited accountability breakdowns that extend de facto forms of safety-net support for institutions and instruments that reach far beyond the limits of de jure coverages. The major problem of modern financial regulation is to restore economic logic to the de jure and de facto coverage of country safety nets. In the U.S., claims on banks that are not deposits and claims on instutions that are not banks (e.g., government-sponsored enterprises, mutual funds, and even hedge funds) have managed to extract de facto safety-net support.

The social norms on which the regulatory systems of European countries are built typically weaken regulators' capacity and incentives to intervene strongly and promptly at systemically important banks. Differences in these norms make the effort to coordinate vision, control, and incentives across countries an especially thorny problem. Cross-border activity expands opportunities for insolvent banks (and incentive-conflicted government officials) to hide losses and concentrations in risk exposure from supervisors in home and/or host countries. To lessen this danger, information-sharing arrangements between national regulatory bodies have been expanding as well, but unfortunately at a much slower pace (Dermine, 2003; Garcia and Nieto, 2005; Schoenmaker and Osterloo, 2004; Schüler, 2003).

But being able to monitor bank risk exposures is only part of the cross-border coordination problem. Differences in regulatory authority, instruments, and goals must also be reconciled and imbedded into a cross-border architecture of democratic accountability. Crossborder accountability and emergency tax-collecting capacity mean that whoever manages a multinational safety net must be accountable to the taxpayers of whatever countries supply the 
risk capital safety-net managers can call upon to bail out insolvent institutions in catastrophic circumstances. Because nation-based regulators focus primarily on effects that fall on their own citizens, the costs of banking insolvency in one country could easily spill over onto the accounts of taxpayers in partner countries (Vives, 2001). Moreover, gaps in information flows and jurisdiction delay resolution activity and increase the effective burdens of proof that individualcountry supervisors must meet before they can take needed loss-control actions.

In the EU, cross-country supervision does not entail cross-country insurance. For this reason, the lead-regulator model -- in which home-country regulators examine multinational conglomerates and host-country regulators rely on the results - ignores the principle of democratic accountability. To perform the duties they owe their citizens, supervisors in different countries must be able both to monitor and to discipline one another's supervisory and regulatory activity.

This paper begins by explaining why it is hard to resist, at least as a working hypothesis, the proposition that for the foreseeable future only painful crisis experience - and not the logical force of abstract economic argument—could convince national authorities to cede sufficient tax and regulatory authority to Brussels to permit the construction of an incentive-compatible PanEuropean crisis-prevention and crisis-management agency. The existence of impediments to efficient contracting implies that national banking supervisors would be wise to improve their ability at least to monitor and to respond to differences in the quality of one another's work. The paper goes on to argue that this could be accomplished by asking individualcountry governments and the multinational bodies to encourage all countries to issue tradable countrylevel deposit-insurance agency debt and reinsurance contracts. 


\section{Patterns of Jurisdictional Conflict in U.S. History}

Regulation is re-regulation. Both within and across countries, regulatory arrangements evolve in a dialectical fashion (Kane, 1981). Reforms almost never obliterate pre-existing systems; they amend them at the margin either to lighten perceived burdens or to narrow disruptive loopholes.

The difficulty of moving from a system of independent national regulators to one in which cross-jurisdictional interdependence is efficiently and fairly recognized increases nonlinearly with the number of jurisdictions that must be unified. The antagonism observed between proponents of national and supranational banking supervision in Europe today has many parallels in U.S. history. The United States has experienced more than 200 years of conflict between proponents of state and cross-state (i.e., federal) supervision of its banking system. Initially, state supervisors had the upper hand and markedly extended their power when President Andrew Jackson refused to renew the charter of the Second Bank of the United States in 1836. For the next 25 years, supervisory authority over U.S. banks was exercised wholly by the individual states. However, once a national chartering authority was re-established, jurisdiction began to move slowly and inexorably from the periphery toward the center. The "single passport"- which enables institutions chartered by any one member country both to relocate their headquarters and to operate through branch offices throughout the EU—promises to trigger a similarly slow jurisdictional adjustment.

In any union, the dialectical struggle between joint and individual interests is endless. Increased centralization does not and cannot eliminate the conflicts generated at the periphery. It merely confronts and resolves the conflicts in a different way (Eisenbeis and Wall, 2004). This is why geographic limits on the scope of U.S. banking institutions and federal regulatory 
jurisdiction have yet to attain a stationary equilibrium. Each successive round of adjustment generates a new round of regulation-induced substitute institutional forms and a new set of safety-net stresses.

In debating whether to increase or decrease the degree of centralization in any regulatory system, the opposing sides lay claim to different benefits and routinely exaggerate the costs of the opposing approach. Proponents of decentralization (i.e., states rights) extol the virtues of subsidiarization and regulatory competition and trivialize the burdens of bureaucratic duplication On the other side, proponents of centralization envision outsized benefits from harmonizing and streamlining regulator-bank interfaces and avoiding regulatory duplication, while demonizing regulatory competition as a destructive "race to the bottom."

This dialectical tension sustains a political and economic competition for jurisdiction within and across countries. Jurisdictional competition creates and holds open regulatory gaps and loopholes that banks and competing financial institutions repeatedly turn to their advantage. The regional structure of the Federal Reserve System, the voluntary character of System membership for state-chartered banks, and the preservation of individual-state authority to charter, examine, and close state-licensed institutions underscore the permanence of this competition.

Differences in disciplinary powers and enforcement schemes open "loophole" opportunities for regulatory arbitrage and regulated institutions' lobbying activity encourages jurisdictional competition that leads to incentive-conflicted politicians and regulators to tolerate or widen these loopholes. To offset these measures, it is necessary for taxpayers to be able to monitor the performance of top regulators and to hold them accountable for the quality of their work. 
As long as defects in accountability allow officials to shift losses to taxpayers in ways that in the short run are virtually invisible to outsiders, government-financed deposit-insurance schemes are particularly vulnerable to political pressure to subsidize enterprises whose capital is too small for the risks they have assumed (Demirgüç and Kane, 2003). In his study of 14 statelevel deposit-insurance experiments that preceded the creation of federal deposit insurance, Calomiris (1990, 1992a and b) makes it clear that the only three schemes that forbearance pressures did not bankrupt were ones that were privately managed and strongly incentivized to enforce the principle of unlimited mutual liability. More recently, when accelerating inflation drove interest rates to stratospheric levels during the 1970s and 1980s, jurisdictional competition and weaknesses in accountability for deposit-insurance losses led federal officials (and their counterparts in several states) to suppress critical information, grant regulatory forbearances, and extend new risk-taking opportunities to savings institutions and insolvent large banks (Kane, 1989). Interestingly, in the face of the same economic shocks, differently incentivized managers of the federal credit-union insurance system protected taxpayers from losses by enforcing the unlimited mutual liability for losses that had been built into their scheme (Kane and Hendershott, 1996).

\section{Country-Specific Regulatory Cultures and the Difficulty of Coordinating Them}

Government chartering and supervision of banks and payments systems are nearuniversal phenomena. Regulatory activities may be described as efforts by a trusted Third Party to intervene in the shaping, pricing, and delivery of banking products in one of three ways: by rule-making (e.g., capital requirements); by monitoring and enforcement; or by identifying and resolving insolvencies (i.e., shortages in bank-contributed net worth). 
The 1975 Basel Concordat and subsequent elaborations assign responsibility for consolidated supervision of multinational banking organizations to their home countries, but call for contact and cooperation between host and parent supervisory authorities. In the absence of harmonizing dialogue and cooperation, contractual arrangements tie banking regulators in each country to strictly domestic interests. Existing channels of democratic accountability encourage them to design and operate regulatory enterprises to maximize the politically weighted welfare of their fellow citizens. To enforce a home-country regulator's concern for the welfare of host countries in crisis circumstances, it must be made answerable to host-country citizens.

In banking, depositors and other outside stakeholders may be exposed to loss from fraud, leverage, or earnings volatility without being adequately informed or compensated for the risks entailed. To reduce their exposure to opportunistic behavior, a bank's counterpartie s typically: (1) require the bank to bond itself in various ways to behave honestly and fairly; (2) negotiate a deterrent right to punish offensive behavior; and (3) monitor information on the bank's ongoing performance and condition. Bonding, policing, and monitoring are not costless. The costs vary inversely with the transparency $(\mathrm{T})$ provided by the accounting and disclosure regime under which the bank operates. But policing costs are also a function of outside stakeholders' ability to appreciate the implications of the information they receive and their ability to coordinate deterrent and punitive responses with others.

A principal goal of prudential regulation is to protect society from weaknesses in selfdiscipline and market discipline that might otherwise encourage excessive risk-taking and capital shortages at individual banks. Unconflicted policymakers would seek to remedy weaknesses in transparency, bank bonding and depositor deterrency by developing policies for preventing, detecting, and resolving bank insolvencies that would maximize social welfare. Mishan (1969) 
stipulates that optimal decisions in any policy endeavor produce outcomes that are simultaneously Pareto-efficient and "distributionally preferred" (i.e., they help the representative citizen and avoid antiegalitarian redistributions of income). Because crisis-prevention and resolution policies redistribute wealth, economists need to adopt some version of the Mishan criterion before they can fully assess the efficiency of coordinated efforts to prevent and resolve bank insolvencies.

As stewards of taxpayer resources, this criterion implies that financial regulators owe four duties to the representative taxpayer:

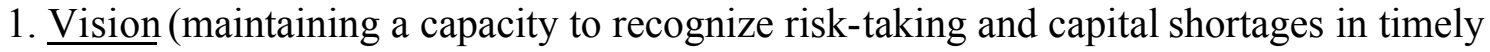
fashion);

2. Prompt corrective action (being committed to control the value of implicit and explicit government guarantees);

3. Least-cost resolution (efficiently curing insolvencies that corrective action fails to avert);

4. Truth-telling (keeping taxpayers informed about the true opportunity costs of regulatory strategies).

Gaps in vision and reporting obligations undermine the effectiveness of both insolvency prevention and crisis resolution. They strengthen short-run political and careerist pressures that tempt top supervisors and regulators to avoid harsh criticism by not closely enforcing economic insolvency.

It is, of course, easier to integrate the private banking markets of any group of countries $(i=1, \ldots, n)$ than to integrate their private and governmental systems of banking regulation. Regulatory integration is complicated because, even if regulatory strategies and control 
structures $\left(\mathrm{R}_{\mathrm{i}}\right)$ did not differ greatly between the countries, individual-country regulators are responsible to different sets of taxpayers $\left(\mathrm{T}_{\mathrm{i}}\right)$ and applicable legislation makes private and governmental regulatory officials accountable to their citizens in disparate contractual ways $\left(\mathrm{C}_{\mathrm{i}}\right)$.

When third-party guarantees don't exist or lose credibility, private markets force banks known to be experiencing opportunity-cost losses to adjust their affairs promptly. Troubled banks must do one or all of three things: shrink their footings, raise more capital, or pay higher interest rates on their deposits and other debt.

In monitoring, disciplining, and resolving banks, the incentives of government officials to act promptly differ from those of private creditors in important ways. Officials cannot focus only on the projected economic costs and benefits of the intervention; they must also estimate outside political responses to their interventions. This is important because official interventions usually generate more publicity than private ones. Savvy government regulators must be alert to how even small interventions might damage their professional reputations and careers if their policies greatly distress powerful parties.

Although many commonalities of interest exist, governmental systems for setting and enforcing financial rules are infested with incent ive conflict. Even within a country, major conflicts exist between and among:

1. Regulators and the firms they regulate;

2. Particular regulators and other societal watchdogs;

3. Regulators and the politicians to whom they must report;

4. Taxpayers and the politicians and regulators they put in office.

How a country traditionally approaches and resolves these conflicts is in part hard-wired into its political and institutional structure. For example, while many EU countries supervise 
banks separately from other financial institutions, some do not. A few European countries (Austria, Denmark, Germany, Sweden, and the United Kingdom, in particular) have established agencies that supervise bank and nonbank financial institutions in an integrated way; others have to some degree integrated the oversight of at least their bank and securities sectors (Schüler, 2003).

Every country relies on regulators and other professional watchdogs to bridge gaps in the bonding, deterrent rights (deterrency), and transparency inherent in its private contracting environment. Over time, the interaction of private and government watchdogs generates a regulatory culture. A culture may be defined as customs, ideas, and attitudes that members of a group share and transmit from generation to generation by systems of subtle and unsubtle rewards and punishments. A regulatory culture limits the ways in which an uncooperative or even unscrupulous individual bank can be monitored and disciplined. It comprises a matrix of attitudes and beliefs about how regulators should act. These slowly changing attitudes and beliefs often express a distrust of government power that traces back to abuses observed in a possibly distant past when the country was occupied, colonized, or run by a one-party government. The culture's taboos and traditions define standards for the fair use of government power. Behind these standards are higher-order social norms that underlie a nation's political and legal environments.

The character of a country's Regulatory Culture is spanned by six specific components:

- Legal authority and reporting obligations

- Formulation and promulgation of specific rules

- Technology of monitoring for violations \& compliance

- Allowable penalties for material violations 
- Duties of consultation: To guarantee fairness, regulated parties enjoy a right to procedural due process that specifies burdens of proof that regulators that must meet before levying specific penalties

- Regulatee rights to judicial review: To bond the fairness guarantee, penalized parties have access to inside and outside appeals procedures.

In large part, the details of each component are shaped by:

a. Recognition and response lags generated by the interaction of weakness in the transparency of the nation's accounting system with bureaucratic incentives and statutory and bureaucratic checks and balances;

b. Regulatory competition brought about by the entry of foreign or differently regulated institutions;

c. Regulatory personnel's exposure to influence activity from a discipline-resistant firm's political clout, consultation rights, and appeal privileges;

d. Social norms that protect fraudsters and bumblers against prompt regulatory discipline.

Lobbying activity seeks to reshape the particular objectives that officials pursue and to constrain the tradeoffs they make within limits set by a country's regulatory culture. How the particular policy strategies officials adopt actually work is determined by regulatees' ability to delay or stymie decisive intervention and to find and exploit circumventive loopholes. Some of these loopholes involve the ability to relocate loss exposures that are more closely supervised by the home country (or a particular host) to venues that monitor or discipline them less effectively. In the absence of cross-country understandings or agreements, it is reasonable to presume that regulators in any individual country A would focus on the politically weighted welfare of its 
own citizens. They would maximize the welfare function, $\mathrm{W}_{\mathrm{A}}\left(\mathrm{R}_{\mathrm{A}} ; \mathrm{C}_{\mathrm{A}} ; \mathbf{R}_{\mathrm{Z}}\right)$, with respect to the instruments and authority conveyed to them by the regulatory culture of $\mathrm{A}$, taking as given the regulatory culture and systems in the vector of other union countries $Z\left(\mathbf{R}_{\mathbf{Z}}\right)$. Similarly, authorities in each other country $\left(Z_{1}, \ldots, Z_{n}\right)$ would maximize $W_{Z_{i}}\left(R_{Z i} ; C_{Z} ; \mathbf{R}_{\mathbf{X}}\right)$, taking $\mathbf{R}_{\mathbf{X}}(=$ $\mathrm{R}_{\mathrm{A}}$ and other Rs) as given. It is convenient to label the solutions to these uncoordinated maximizations as $\mathrm{W}_{\mathrm{A}}^{*}$ and $\mathbf{W}_{\mathbf{Z}}^{*}$.

Assuming that cross-country conflicts are roughly symmetric, it is sufficient to focus on the effect of allowing regulators in A to influence $\mathbf{R}_{\mathbf{Z}}$. The simplest case is to designate A as the prudential regulator for all of the banks that operate in $\mathrm{Z}$ and to allow A to set a single set of rules and procedures $R_{Z_{i}}=R_{A}=R$ for all $i$. We can label the solution that would emerge after this "regulatory centralization" as $\mathrm{W}_{\mathrm{A}}^{\mathrm{C}}$, where the $\mathrm{C}$ stands for "common." Whenever the common R set by A differs from one or both of the systems $\mathrm{W}_{\mathrm{A}}^{*}$ and $\mathbf{W}_{\mathbf{Z}}^{*}$, the welfare of citizens in particular countries change. In theory, the practical restriction that the centralized regulatory regime must be the same in each country, but must respond to at least some distinctive features of each financial environment in $\mathrm{Z}$ could mean that the centralized regulator might end up reducing taxpayer welfare in all countries. Such possibilities are what make a common scheme fiendishly hard both to negotiate in the first place and (until and unless a crisis emerges) only slightly easier to renegotiate over time.

\section{Similarities and Differences in EU Deposit-Insurance Systems}

EU deposit-insurance systems show three common features that-according to U.S. experience and econometric cross-country research summarized in Demirgüç-Kunt, Kane, and 
Laeven (2005) — undermine a country's ability to control moral hazard: membership is not compulsory; funding for payouts is publicly administered; and guarantees extend to interbank deposits. Both individually and in the aggregate, these features reduce incentives for strong institutions to help government supervisors to discipline risk exposures at weak or overly aggressive banks.

On the other hand, these systems differ in important ways: in age (i.e., seasoning), in coverage levels, in the use of coinsurance provisions, in whether they cover balances held in foreign-currency accounts, and in the use they make of private managers. An important consequence of home-country supervision is that member countries have had few incentives to examine and reconcile undesirable differences in the structure of their deposit-insurance systems.

Table 1 shows how widely EU deposit-insurance systems vary in seasoning and in their strategies for limiting their exposure to loss. Only about half of the countries impose coinsurance obligations on depositors. Although an EU Directive establishes a minimum coverage of 20,000 euros, member states are free to set higher levels of compensation. Variation in the ratio of maximum coverage to per capita GDP (pcgdp) ranges from 40 percent in Luxembourg to 480 percent in Italy. Variation in coverage appears even wider if we deflate coverage limits by per capita deposits instead of pcgdp.

Figure 1 expresses 2003 pcgdp in each EU member as a percentage of pcgdp in Luxembourg. Across the EU, variations in individual features correlate -- albeit imperfectly -with per capita GDP and also with various indices of political competitiveness, bureaucratic quality, and government corruption. Per capita GDP also correlates loosely with the quality of a country's contracting environment (i.e., with the degree of transparency, bonding, and deterrency found in private and government contracts). Where private contracting environments are strong 
or government accountability is weak, net marginal benefits from offering extensive government guarantees are hard to achieve.

With the recent entrance of transitional Eastern European countries into the EU, the potential for multinational banking distress seems greater than it was in the relatively benign 1975-1997 period studied by Hutchinson (2002). In the event of a threatened regional crisis or indeed of insolvency at any multinational bank, one would expect large depositors to work with bank personnel to arbitrage cross-country differences in effective coverages. A large depositor could increase statutory coverage for balances by spreading its aggregate claim against the conglomerate banking organization across branches and locally incorporated subsidiaries in different member countries. Recognizing that the likelihood of a government's "topping up" payouts beyond statutory coverages would grow with a country's fiscal capacity, such a depositor could further strengthen the collectability of its aggregate claim by relocating deposit balances from branches and subsidiaries in countries with low tax-collection and debt capacities and low coverage limits (such as Hungary) to countries with stronger tax-collection and debt capacities and very high coverage limits (such as France and Italy).

Unlike traditional deposit runs which simply remove funds from a troubled institution, protective deposit rebooking could preserve the liquidity and risk-taking capacity of the consolidated organization while generating capricious pressure on individual countries' balance of payments and deposit-insurance liabilities. Within the European Monetary Union, exchangerate adjustments could not occur, so that interbank loans and adjustments in income and employment would have to perform the necessary equilibrations. However, for countries outside the monetary union, an intrabank deposit run could also affect foreign-exchange rates, so that the mix of currency, income, and employment adjustments would depend on whether and how the 
affected institution is able to borrow from foreign banks and how it elects to manage its resulting exposure to currency risks.

\section{Regulatory Arbitrage and Regulatory Competition}

Within and across countries, the services performed by financial institutions and financial safety nets are jointly determined. The size and distribution of the net social benefits or costs produced by regulatory services vary substantially from country to country. This variation fuels interactive process of regulatory arbitrage and regulatory competition (Kane, 1981). An aggressive regulator can increase its budget and prestige by enhancing the quality and reliability of important services its regulatees offer to customers. In turn, aggressive institutions can modify the form and location of their services to extract taxpayer-financed net benefits from individualcountry safety nets.

When the value of a deposit insurer's implicit and explicit guarantees of clientinstitutions obligations exceeds the fees and implicit costs the insurer imposes on them, its system offers regulatory clients a net regulatory benefit. In the (seldom observed) reverse case, the insurance system would generate a net burden. Regulatory arbitrage occurs when differences in effective burdens and benefits induce institutions to adjust their organizational form to book particular balance-sheet positions in jurisdictions that treat these categories of deal-making most favorably. Because financial deals and services may be conceived and executed in locations different from those in which profits and costs formally accrue, the simplest form of regulatory arbitrage consists of introducing into a firm's organization chart a "booking division” whose job it is to restructure the institution's deal-making contracts and services-delivery mechanisms so that its revenues and costs are allocated across nations in an advantageous fashion. 
As a straightforward example, let's suppose that country A levies semiannual depositinsurance premiums on deposit balances in banking offices located within its borders on March 31 and September 30, while premiums in Z are based on June 30 and December 31 amounts. On each country's assessment date, it would pay the booking division of every bank that accepted deposits in both countries to shuffle at least some of the balances of its multinational customers to offices in the other country.

In most regulatory cultures, a multinational bank's booking division imposes more competitive discipline on country-level regulators than taxpayers can. A high-burden regulator loses budget revenue, clients, bureaucratic rents, and prestige, but market forces can seldom force a poorly performing regulator to shut down. Its continued existence is supported by incentive defects in public-service contracting and information exchange between government regulators and taxpayer-suppliers of their risk capital. At best, governments are prepared to shift the functions of a poorly performing regulator into a new agency. Although losses generate political and bureaucratic pressures on enfeebled regulators to rebuild their market share, the curtailment of exit pressure lessens the incentive for incumbent politicians and regulators to respond to regulatory arbitrage by increasing the efficiency of their system. They may attempt instead — or as well — to form cross-country regulatory cartels and to curtail industry criticism during their watch by offering client constituencies hard-to-observe increases in supervisory and regulatory subsidies (see, for example, Hoshi, 2002). The more difficult it is for the press to uncover and report the costs that responses of this kind impose on taxpayers, the longer it takes disadvantaged parties to assemble enough lobbying counterpressure to hold regulators accountable for these costs. This is why the speed and extent to which regulatory competition 
leads to better regulation on average varies with the quality of the performance reporting and cultural norms a given regulatory culture entails.

\section{Consolidating versus Trading Individual-Country Exposures}

Completely autonomous national deposit-insurance systems pose two problems of coordination. The first comes from the difficulty of identifying and mending destabilizing elements in individual-country loss-control systems before they can harm other countries. The second is the absence of contractual mechanisms for an adversely affected country to discipline authorities in a problem country or even to hedge straightforwardly whatever cross-country risk exposures it might face.

For countries that have adopted a common currency, it seems natural to address these coordination problems by consolidating deposit-insurance management (Schoenmaker and Osterloo, 2004). To see the problems in this alleged solution, it is helpful to envision a consolidated deposit insurer as a centrally managed holding company whose managers would more or less tightly oversee insurance subsidiaries operating in individual countries. The principal tasks of the holding company would be to measure, manage, and fund cross-country risk, including the risk of a contagious transmission of financial-crisis pressur es from one country to another. However, the central office would have to respect differences in regulatory culture. The extent of these differences and their resistance to rapid change would limit how fast and how extensively consolidation could proceed.

Public-choice theory presumes that public officials can more easily create standards and enforcement schemes that internalize externalities within a country or particular "regulatory culture" than across countries or cultures. Diversity in societal norms, the uneven pace of 
financial change, and the length of individual-country and cross-country regulatory lags make differences in adaptive capacity the central issue in coordinating banking supervision.

Although instructive parallels exist between the potential consolidation of modern European deposit-insurance enterprises and the U.S. transition from state-level to federal deposit insurance, the parallel falls short in three ways. First, although state systems were governmentcreated and government-supervised, they were funded entirely from client premiums. Second, none of these systems was still in operation when cross-state consolidation was negotiated. This simplified the turf issues that negotiators faced. Third, the design of the consolidated enterprise was worked out in a democratically elected national legislature, subject to a system of fully seasoned checks and balances from judiciary and executive branches of government.

In the EU today, cross-country cooperation to lessen externalities has to be negotiated on an $\underline{\text { ad }}$ hoc basis in European Union committees and ministries. The formulation and subsequent enforceability of any multinational agreement that might emerge would be weakened by holes in still-evolving checks and balances and by divergences in individual-country cultural norms, differences in market and political structures, and variation in exposures to economic stress.

As implicit guarantors of catastrophic losses, taxpayers in individual EU countries resemble poorly informed corporate shareholders. Taxpayers' inability either to observe their implicit loss exposure or to extract appropriate compensation leaves them vulnerable to exploitation by consolidated and individuatcountry regulators. A norm of nationalism is enshrined in every regulatory culture. This norm distorts accountability for multinational losses and undermines efforts either to empower or to oblige a consolidated supervisor or its countrylevel subsidiaries to minimize the aggregate costs of incentive conflict. 
To manage externalities within the European Union, supranational managers could eschew direct supervision and simply trade the functional equivalent of reinsurance contracts informally within an intrafirm "capital market." However, information asymmetries and incentive conflicts within the opaque intercorporate network would still degrade the adjustment process. Only in a perfect world could beneficent regulators in individual countries and the taxpayer-principals they serve always know what coordinated adjustments in safety-net parameters would maximize world or regional welfare and proceed to make these adjustments promptly. In the real world, the alleged optimality of proposed adjustments is always contested and regulators' incentives to undertake desirable adjustments are distorted by information lags, nationalistic biases, variation in empowerments and reporting responsibilities, lega 1 systems, and cultural norms.

Once politicians were presented with strong evidence that cross-country deposit churning had contributed to an observed crisis, it is likely that the cause of rapid safety-net consolidation would win important new adherents. However, waiting for unpleasant evidence to develop seems a poor way to address the externalities involved.

The rest of this paper argues that conflicts of interest between national deposit insurers and domestic and foreign taxpayers could be lessened and economic efficiency increased if the transparency and deterrency of country-level deposit-insurance loss exposures could be enhanced. To do this without multinational negotiations, individualcountry authorities could merely acquiesce in providing new and market-driven ways to measure and fund their particular safety-net risk exposures. Kane (2003) suggests that this could be done by organizing public markets in deposit insurers' debt and reinsurance derivatives. Trading contracts that reinsure designated shares ("tranches") of observable disbursements made in resolving bank insolvencies 
within specified windows of time would allow governments to smooth their expenses over the business cycle and to transfer selected deposit-insurance risks both to one another and to private counterparties. Unlike intercorporate risk transfers, public trading in reinsurance contracts would be transparent and could even be routed through an organized exchange. Prices established in debt and derivatives markets would disclose traders' consensus estimates of changing national loss exposures and do so without making any government cede politically sensitive monitoring, policing, or closure powers to a supranational entity.

VI. Value of Conceiving of Deposit-Insurance Contracts as Tradable Credit Derivatives A government deposit-insurance guarantee (DIG) correspond s to one side of a plainvanilla credit default swap (CDS) supporting a designated first-loss exposures in underlying deposit instruments. Every CDS transfers the default-risk exposure to one or more named borrowers (here, insured banks) from a protection receiver (here, a depositor) to a third party that is willing and able to bear this exposure (here, the deposit insurer). In deposit insurance, the original protection seller has the statutory right and duty to supervise proactively the institutions whose deposits it covers. The better this protection seller can carry out its supervisory responsibilities, the less risk exposure it and its counterparties actually share.

In return for covering the default risk in the protection receiver's long position in the underlying instrument, the DIG protection seller receives contractually defined intervention rights and collects a periodic fee from each bank it guarantees. In a fully competitive equilibrium, the insurer's loss-control system would be Pareto-optimal and the fee would cover the sum of the costs $(\mathrm{C})$ of the protection seller's supervisory and portfolio activity and the market value of the risk exposure it assumes (R). If the loss-control system were imperfect but 
costless to operate, the premium would equal R. If a country's loss-control system were both perfect and costless, the equilibrium $\mathrm{R}$ and periodic premium would be zero.

Although deposit insurance also resembles a casualty insurance policy (CIP), the correspondence breaks down in one important respect. Deposit insurance and CIP are alike in that:

- Payouts are triggered by a well-defined loss-causing event;

- One party is designated as providing (i.e., selling) "protection against the covered event;"

- The party literally "buying protection" (here, the bank on behalf of the depositor) pays a fee to the protection seller on a periodic basis as long as the coverage exists;

- The contract stipulates how the loss associated with an insured event will be measured and how soon claims for damage will be paid;

- The protection buyer must have an "insurable position" (i.e., hold a long position in the covered asset).

The critical difference between a CIP and a government-issued deposit-insurance contract is that the insured party in a CIP has an obligation to prove the size of its loss using professional appraisers and the insurer has both a right and a duty to challenge the proffered proof. The resulting negotiation process is called "loss adjustment." Both in deposit insurance and in credit swaps, the value of the protection payment is preadjusted. Payment is governed by actual price movements in the underlying instrument during the days and weeks covered by the contract. For a CDS, the protection payment is determined by the price movement experienced by a "reference security" during a specified number of days or weeks following the default event. In contrast, assuming there is no coinsurance or deductible, a DIG pays out the par value of insured deposits and the insurer takes control of the insolvent bank. As receiver, the insurer either sells its 
ownership position to another party or it puts the bank's assets into liquidation Whenever a failed bank is sold off promptly, the cost of protection is established as the difference between the outpayments made to depositors and the net proceeds from the sale. However, in the event the insurer decides to liquidate the bank, the cost of protection remains stochastic and may not be known for several years. For this reason, tradable deposit-insurance derivative contracts might specify an operational procedure for valuing and transferring the expected value of proceeds from the liquidation. Alternatively, the protection-supplying side of DIG reinsurance contracts could be assigned a tradable claim to the actual cash flows generated during the liquidation.

An additional feature of a freely tradable CDS — and, therefore, of tradable depositinsurance derivative contracts - is that the protection buyer need not hold a long position in the covered asset and the short side need not be empowered to exercise any supervisory functions. In a negotiable DIG derivative contract, any party anywhere in the world could take either side of the default swap as long as its own credit standing and the contract's bonding arrangements were strong enough to control the risk of counterparty nonperformance and the trader thought it could make a profit. Private parties entering either side of any swap would seek to uncover nonpublic information and they would communicate their findings to the market by the trades they make.

As with any other publicly traded instrument, counterparties would buy and sell DIG reinsurance contracts either on an organized exchange or through a network of respected, government-licensed dealers. These market makers would accept a first-loss responsibility for covering shortfalls in performance by any counterparty to whom they sell a reinsurance contract. This responsibility would create incentives for market makers and counterparties to police carefully the wealth and character of one another. 
Of course, projected profits would be conditional on each party's assessment of: (1) the capital and risk exposures of the banks and counterparties that each contract covers, and (2) the quality of countries' systems of safety-net loss control. Financial analysts could use the prices of various derivatives issued directly by a country's major banks to approximate the value of individual-country DIG exposures. Comparing these hypothetical values with the actual prices at which the reinsurance derivatives trade could help DIG officials in individual EU countries to identify their cross-country exposures to loss. Unmasking these risk should encourage officials to undertake trades and supervisory actions designed to rein in any exposures that disconcert them.

Every trader that takes either side of a DIG derivative enters into a de facto partnership with the insurer of the underlying contract. Kane, Hickman, and Burger (1993) explain why coinsurance and reinsurance partnerships between private and government deposit insurers are socially beneficial. Such partnerships allow the government to outsource to private counterparties risks and skills in which private parties have a comparative advantage. The result is to integrate the timeliness and greater accountability of private initiatives with the deep-pocket back-up protection of individualcountry guarantees against catastrophic risk.

During their lives, each private reinsurance contract would convey a specified tranche of the aggregate losses a particular insurer incurred between specified upper and lower limits. The more efficient an insurer's monitoring, insolvency-resolution, and liquidation efforts, the smaller and rarer will be the losses that the reinsurers would expect to bear. As confidence grows in a particular insurer's loss-control system, the upper limit may be raised (to lessen taxpayer loss exposure) and reinsurance shares may be subdivided into finer and finer tranches. 
VII. Model of Balance-Sheet Management at a Deposit-Insurance Enterprise

Kane (2003) and Draghi, Giavazzi, and Merton (2003) model a country’s deposit insurer as a firm in which taxpayers and insured institutions invest risk capital. As illustrated in Figure 1, an insurer's balance sheet consists of four controllable items: (1) a portfolio of tangible assets that constitutes its loss reserves (A); (2) the aggregate value of the intangible net loss exposures $\mathrm{L}_{\mathrm{i}}$ that pass through from its individual client banks $(\mathrm{i}=1, \ldots, \mathrm{n}) ;(3)$ a book of external hedges (H); and (4) the value of its risk capital (R). The value of each $\mathrm{L}_{\mathrm{i}}$ is defined to be net of the "internal" diversification benefits that correlations among the other (n-1) exposures an individual insurer's clients might naturally generate. This paper extends prior models by investigating how each loss exposure varies with the quality (Q) and cost (C) of the insurer's system for monitoring and deterring client risk taking. Another innovation is that $\mathrm{Q}$ is portrayed as a function of the transparency $(\mathrm{T})$ that the monitoring system generates and the effect of the bonding $(\mathrm{B})$ and deterrent restrictions (D) that depositors and the insurer use to restrain bank risk taking.

If loss exposures are managed efficiently, the economic value of $\mathrm{R}$ supports a profile of risk from which all diversifiable risk has been removed by booking external hedges until the marginal benefit of further hed ging transactions equals their marginal hedging cost. What levels of $\mathrm{T}, \mathrm{B}$, and $\mathrm{D}$ the insurer establishes and how benefits and costs are distributed between managers, clients, and taxpayers is a matter of corporate governance. Accountability for these decisions depends on the relative ability of the insurer's capital-supplying sectors to monitor the insurer's aggregate loss exposure and to influence managerial decisions in a country's particular political and financial-contracting environment. 
To manage the portfolio risk a deposit insurer incurs, its staff must measure, price, and hedge its loss exposures and calculate an appropriate level of reserves. This risk is managed optimally when the marginal costs of all four activities are set equal to their marginal benefits.

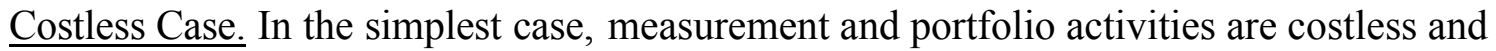
risk exposures are known and stationary. In this case, the insurer would charge each client only for operating costs $(\mathrm{C})$ and the undiversifiable risk that client imposed on insurance reserves and these charges would allow the insurer to maintain an optimal fund of explicit reserves and intangible taxpayer catastrophic support. Assuming that the loss exposures in an insurer's client base do not cancel out across its country-level client base, the insurer could either hedge its idiosyncratic risk in global reinsurance markets or consolidate structurally with other countries' insurers until all diversifiable risk disappeared from the system. Unless operating costs differed in an important way, it would make no difference what combination of hedging and consolidation activities management chose to pursue (Kane, 2003).

$\underline{\text { Introducing Measurement and Pricing Costs. Realistically, deposit-insurance managers }}$ must incur positive costs to measure and price their loss exposures. This makes it uneconomic to pursue these activities until their marginal benefits are driven to zero. Also, individual-country and global insurers can only estimate their efficient risk-return frontiers.

When key parameters are both uncertain and nonstationary, information lags and bureaucratic restraints on policy response make risk harder to measure and also make responsibility for the costs of policy mistakes harder to assign. Suppliers of deposit-insurance capital need to worry about how to hold country-level and relevant multinational officials accountable for the tradeoff between the public and private benefits imbedded in the balancesheet structure and loss-control system they choose. 
Even in a stationary environment, imperfections in information flow support agency costs that would be resolved differently under consolidation than under a cross-country hedging strategy. The greater transparency of the costs and discipline generated in hedging particular exposures in external reinsurance markets renders them more contractable than the costs of operating a cross-country corporate structure and subjecting its managers to a governance system strong enough to control incentive conflict in the consolidated enterprise.

In deposit insurance, the probability of large shocks (so called "jump risk") is nonnegligible and supervisors must allow for the possibility that large shocks may move across countries with greater force than small ones. The infrequent occurrence of large shocks means that policymakers have an insufficient number of observations with which to estimate reliably the behavior of cross-country correlation coefficients in crisis circumstances. Experience indicates that correlations among risky assets tend to rise during financial crises (see, e.g., Goetzman, $\mathrm{Li}$, and Rouwenhorst, 2005). This suggests that a country's pre-existing exposures to losses in other countries might lose their diversifying power and increase contagion at critical moments. Even so, public trading of risk exposures by country-level managers would deal better with correlation instability because it would generate incentives for quicker and better-informed responses by partner countries. In contrast, managers of a centralized holding company that traded country loss exposures only in informationally and politically constrained internal capital markets would be much slower to reallocate substantial amounts of risk capital across countries when correlations change.

The key point is that investors in transparent derivatives markets and the top managers of a centralized holding company would have different ways of coordinating, verifying, and acting on information that is collected at the country level and released by incentive-conflicted agents. 
To overcome bureaucratic barriers to the efficient allocation of its risk capital, the multinational regulatory holding company would have to establish an information system and a structure of implicit and explicit compensation that could induce a high level of truth-telling, promise keeping, and fair play both within and across its country-level subsidiaries. However, in tough times, holding-company management would retain the option to decide just what information about changing cross-country risk gets reported publicly to capital suppliers in the subsidiary countries. When sudden adverse shocks increase the fragility of important banks in country banking systems, the holding company is unlikely to report fully or accurately the spreads at which it is clearing different countries' exposures. Suppressing such information promises to prevent bank runs during each top manager's particular watch on the bridge, but over longer periods it would shift more and more systemic risk onto insurance reserves. This is because hiding the weakness of troubled banks insulates bank managers from healthy depositor discipline and encourages them to risk deeper and deeper levels of insolvency in the future.

Given that information on country-level loss exposures is imperfect, a major advantage of competitive trading in deposit-insurance derivatives is that it would provide a way to reward private analysts for uncovering information about the size of individual-country loss exposures and the quality of regulatory performance. Although country-level loss exposures are bound to vary over the life of any derivatives contract, experience indicates that bureaucrats in individual countries are reluctant both to face up to adverse shifts or to publicize them honestly when they first recognize them. Rather than letting incentive-conflicted holding-company executives delay the release of information about changes in insolvency risk, derivatives trading would immediately disclose changes in the market's willingness to assume a particular insurer's loss exposures. 
Although our analysis emphasizes cross-country benefits, trading deposit-insurance derivatives would improve managerical incentives at any deposit insurer that issued them. Movements in the spreads observed for country-level derivatives would generate data on the changing value of a country's exposure to particular layers of loss. By dissecting and reassembling the prices at which DIG derivatives trade, financial analysts could construct and disseminate in timely fashion market-based estimates of the value of stakeholder loss exposures.

Each contract traded would establish an implicit partnership between the insurer, reinsurance market-makers, and contractual counterparties. In contrast to the real options that managers retain under current arrangements, each reinsurance partnership would assign private loss-bearers a series of well-defined and tradable loss exposures. Variation in the market price established for individual-country contracts wo uld surface new data about the relative performance of particular supervisory systems. Whenever a country-level deposit insurer wanted its reinsurance derivative contracts to sell at a lower price, it would only have to formulate, disclose, and bond itself to carry out an improved loss-control strategy.

\section{Summary}

This paper emphasizes that differences in regulatory culture are a largely exogenous constraint on the problem of finding and negotiating efficient ways to identify and internalize deposit-insurance externalities across countries. It advances three hypotheses. First, in the absence of crisis, few pairs of national deposit-insurance schemes could readily integrate their particular regulatory systems. Second, divergences in regulatory culture make consolidation an unpromising way for deposit insurers in any multinational community to address cross-country externalities today. Third, opening opportunities to trade structured reinsurance derivatives 
could improve the efficiency of every deposit insurer that issued them and achieve many of the putative benefits of multinational supervisory consolidation without sacrificing the democratic accountability inherent in the current system of country-level policymaking.

Much as protection sellers function in existing credit-swap markets, buyers of the reinsurance derivatives proposed here would accept a synthetic position in one or more layers of the actual expenses incurred in resolving individual-bank insolvencies in particular countries during specified time periods. Over time, the price a given insurer would pay for successive units of protection would vary inversely with the condition of its banks and directly with increases in the perceived quality of its loss-control system.

Differences in the spreads quoted on DIG derivatives for different countries would offer irrepressible early-warning signals of the relative weakness and strength of different countries' crisis-prevention and crisis-management systems. The public nature of these signals and the contractual right to offload losses would counter unhealthful political and bureaucratic pressure to postpone the treatment of emerging problems.

The observable benefits of achieving a lower spread would strengthen incentives for improving individualcountry insurance systems even at times when their loss exposures were not surging out of control. If national stock exchanges or the deposit insurers of major countries were to propose and foster trading in DIG derivatives, the desire to improve market spreads would encourage policymakers in individual countries to improve their regulatory systems. Making movements in spreads observable would also make it easier for empirical researchers to identify the effectiveness of alternative design features and enforcement techniques. 
December 5, 2005

\section{REFERENCES}

Calomiris, Charles, 1990. "Is Deposit Insurance Necessary?: A Historical Perspective," The Journal of Economic History, 50(June), 283-295.

, 1992a. "Getting the Incentives Right in the Current Deposit Insurance System: Successes from the pre-FDIC Era," in James Barth and R. Dan Brumbaugh (ed.), The Reform of Deposit Insurance: Disciplining Government and Protecting Taxpayers, New York: Harper Collins, pp. 13-35.

, 1992b. "Do 'Vulnerable' Economies Need Deposit Insurance?: Lessons from U.S. Agriculture in the 1920s," and "Response" in Philip L. Brock (ed.), If Texas Were Chile: A Primer on Banking Reform, San Francisco: Institute for Contemporary Studies Press, pp. 237-314 and pp. 319-328.

Demirgüç, Asli, and Edward J. Kane, 2002. "Deposit Insurance Around the Globe: Where Does it Work?" Journal of Economic Perspectives, 16(Spring), 175-195.

Demirgüç-Kunt, Asli, Edward J. Kane, and Luc Laeven, 2005. "Determinants of Deposit Insurance Adoption and Design." World Bank and Boston College (unpublished).

Dermine, Jean, 2003. European Banking: Past, Present and Future, in The Transformation of the European Financial System, V. Gaspar, P. Hartmann, and O. Sleijpen (eds.). Frankfurt: European Central Bank, 31-95.

Draghi, Mario, Francesco Giavazzi, and Robert C. Merton, 2003. “Transparency, Risk Management and International Financial Fragility," Harvard Business School (September 24).

Eisenbeis, Robert A., and Larry Wall, 2004. "Agency Problems in Banking Supervision: The Case of the EMU." Presented at a September 2-3 conference on The Structure of Regulation in Helsinki, Finland.

Garcia, Gillian and Maria Nieto, 2005. "Banking Crisis Management in the European Union: Multiple Regulators and Resolution Authorities” (unpublished).

Goetzman, William N., Lingfeng Li, and K. Geert Rouwenhorst, 2005. "Long-Term Global Market Correlations," Journal of Business, 78(January), 1-38.

Hoshi, Takeo, 2002. "The Convoy System for Insolvent Banks: How it Originally Worked and Why it Failed in the 1990s," Japan and the World Economy, 14, pp. 155-180. 
Hutchinson, Michael M., 2002. "European Banking Distress and EMU: Institutional and Macroeconomic Risks." Scandinavian Journal of Economics, 104(no. 3), 365-389.

Kane, Edward J., 1981. "Accelerating Inflation, Technological Innovation, and the Decreasing Effectiveness of Banking Regulation, Journal of Finance, 36(May), 355367.

, 1989. The S\&L Insurance Mess: How Did It Happen? Washington: The Urban Institute Press.

, 2003. "What Kind of Multinational Deposit-Insurance Arrangements Might Best Enhance World Welfare?" Pacific-Basin Finance Journal, 11(September), 413428.

, 2005: "Confronting Divergent Interests in Cross-Border Regulatory Arrangements," Conference on Cross-Border Banking: The Regulatory Challenge, Federal Reserve Bank of Chicago (October).

and Robert Hendershott, 1996. "The Federal Deposit Insurance Fund that Didn't Put a Bite on U.S. Taxpayers.” Journal of Banking and Finance, 10(September), 1305-1327.

, James C. Hickman, and Abert E. Burger, 1993. Implementing a PrivateFederal Deposit Insurance Partnership, Madison: Center for Credit Union Research and the Filene Research Institute.

Mishan, E.J., 1969. Welfare Economics: An Assessment, Amsterdam and London: North Holland Publishing Company

Schoenmaker, Dirk, and Sander Osterloo, 2004. "Cross-Border Issues in European Financial Supervision," in D. Mayes and G. Wood (eds.), The Structure of Financial Regulation. London: Routledge (forthcoming).

Schüler, Martin, 2003: "How Do Banking Supervisors Deal with Europe-Wide Systemic Risk?" Centre for European Economic Research, Discussion Paper No. 03-03.

Vives, Xavier, 2001. "Restructuring Financial Regulation in the European Monetary Union," Journal of Financial Services Research, 19 (February, 57-82. 
December 5, 2005

Table 1: Variation in GDP Per Capita, Deposit-Insurance Coverage Limits, and Coinsurance Provisions in European Union Counties, in 2002 and 2003

\begin{tabular}{|c|c|c|c|c|c|c|c|}
\hline Country & $\begin{array}{c}\text { Date } \\
\text { enacted }\end{array}$ & $\begin{array}{c}\text { Coverage } \\
\text { limit in } 2003 \\
\text { (in US\$) }\end{array}$ & $\begin{array}{c}\text { GDP per capita } \\
\text { in } 2003 \\
\text { (in } 1999 \text { US\$) }\end{array}$ & $\begin{array}{l}\text { Coverage limit-to- } \\
\text { GDP per capita in } \\
2002\end{array}$ & $\begin{array}{l}\text { Coverage ratio } \\
\text { adjusted for } \\
\text { coinsurance in } \\
2002 \\
\end{array}$ & $\begin{array}{l}\text { Maximum } \\
\text { Coinsurance } \\
(\text { in \%) in } 2002 \\
\end{array}$ & $\begin{array}{l}\text { Coverage limit-to- } \\
\text { deposits per capita } \\
\text { in } 2002 \\
\end{array}$ \\
\hline Austria & 1979 & 25,260 & 32,049 & 0.8 & 0.7 & 10 & 0.9 \\
\hline Belgium & 1974 & 25,260 & 29,889 & 0.8 & 0.7 & 10 & 0.9 \\
\hline Cyprus & 2000 & 25,260 & 13,467 & 2.5 & 2.2 & 10 & 2 \\
\hline Czech Republic & 1994 & 31,575 & 5,207 & 3.6 & 3.2 & 10 & 5.3 \\
\hline Denmark & 1988 & 40,296 & 37,500 & 1.2 & 1.2 & 0 & 2.5 \\
\hline Estonia & 1998 & 8,058 & 4,148 & 0.5 & 0.4 & 10 & 1.4 \\
\hline Finland & 1969 & 31,863 & 30,332 & 0.9 & 0.9 & 0 & 1.9 \\
\hline France & 1980 & 88,410 & 29,133 & 2.7 & 2.7 & 0 & 4.2 \\
\hline Germany & 1966 & 25,260 & 31,773 & 0.8 & 0.7 & 10 & 0.8 \\
\hline Greece & 1993 & 25,260 & 12,652 & 1.5 & 1.5 & 0 & 1.7 \\
\hline Hungary & 1993 & 14,429 & 5,136 & 0.6 & 0.6 & 0 & 1.5 \\
\hline Ireland & 1989 & 25,260 & 25,497 & 0.6 & 0.5 & 10 & 0.8 \\
\hline Italy & 1987 & 130,457 & 20,302 & 4.8 & 4.8 & 0 & 8.7 \\
\hline Latvia & 1998 & 5,545 & 2,476 & 1.4 & 1.4 & 0 & 5.2 \\
\hline Lithuania & 1996 & 16,293 & 2,215 & 3.1 & 2.8 & $10^{*}$ & 14.1 \\
\hline Luxembourg & 1989 & 25,260 & 53,013 & 0.4 & 0.4 & 10 & 0.1 \\
\hline Malta & 2003 & 25,260 & 9,812 & n.a. & n.a. & n.a. & n.a. \\
\hline Netherlands & 1979 & 25,260 & 30,389 & 0.7 & 0.7 & 0 & 0.7 \\
\hline Poland & 1995 & 28,418 & 3,536 & 3.6 & 3.5 & $10^{*}$ & 14.3 \\
\hline Portugal & 1992 & 31,575 & 12,499 & 1.9 & 1.9 & 0 & 2.1 \\
\hline Slovak Republic & 1996 & 25,260 & 4,180 & 2.8 & 2.8 & 10 & 4.8 \\
\hline Slovenia & 2001 & 26,931 & 11,160 & 1.6 & 1.6 & 0 & 3 \\
\hline Spain & 1977 & 25,260 & 16,824 & 1.2 & 1.2 & 10 & 1.4 \\
\hline Sweden & 1996 & 34,364 & 30,286 & 1 & 1 & 0 & n.a. \\
\hline United Kingdom & 1982 & 19,611 & 21,616 & 2 & 1.8 & $10 *$ & n.a. \\
\hline
\end{tabular}

Source: Demirgüç-Kunt, Kane, and Laeven (2005).

Notes: n.a.: not available

* In these countries, coinsurance applies only for amounts above a designated account size. 


\section{Figure 1}

Dollar Value of 2003 Per Capita GDP in Individual European Union Countries Expressed as a Percentage of the Value for Luxembourg

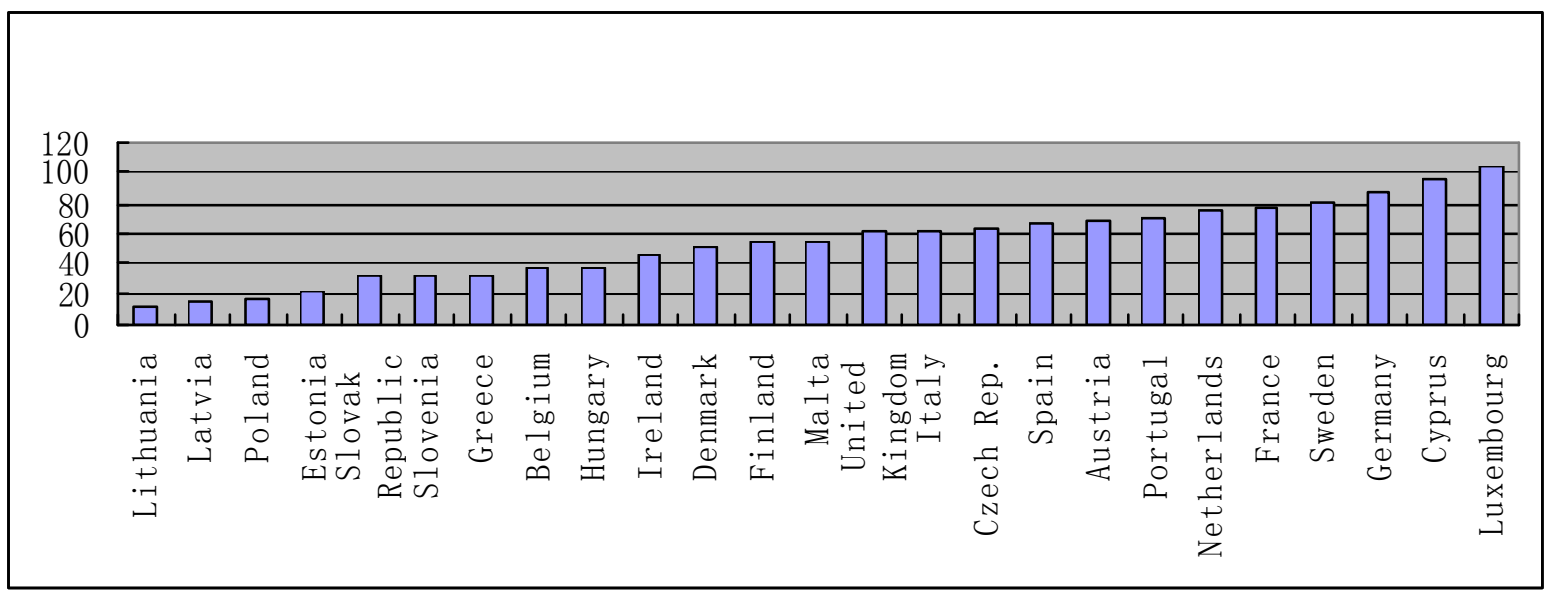


FIGURE TWO: HYPOTHETICAL BALANCE SHEET FOR A DEPOSITINSURANCE ENTERPRISE

\begin{tabular}{l|l}
\hline $\mathrm{A}$ & $\sum_{i=1}^{n} L_{i}[Q(T, D, B)]$ \\
& $\mathrm{H}$ \\
$\mathrm{R}$
\end{tabular}

